\title{
Unanthribus, um novo gênero Neotropical de Ptychoderini Jekel, 1855 (Coleoptera, Anthribidae, Anthribinae) ${ }^{1}$
}

\author{
José Ricardo M. Mermudes ${ }^{2,3}$
}

\begin{abstract}
Unanthribus, a new Neotropical genus of Ptychoderini Jekel, 1855 (Coleoptera, Anthribidae, Anthribinae). Unanthribus gen. nov. is proposed to include Unanthribus maximus sp. nov. (type species) described from Brazil (Pará), and $U$. grandis (Jordan, 1911) comb. nov., which is redescribed. The species are illustrated and keyed.
\end{abstract}

KEYwORDS. Anthribidae; Neotropical; new genus; taxonomy; Unanthribus.

\section{INTRODUÇÃO}

A tribo Ptychoderini Jekel, 1855 está representada por seis gêneros (Alonso-ZARAZAGA \& LyAL 1999): Cerambyrhynchus Montrouzier, 1855, restrito às Ilhas do Sudoeste do Pacífico; Phloeopemon Schoenherr, 1839, das regiões Oriental, Indomalaia e Paleártica; Phloeotragus Schoenherr, 1823, Afrotropical; e os neotropicais Ptychoderes Schoenherr, 1823, Tribotropis Jekel,1855 e Hypselotropis Jekel, 1855.

$\mathrm{O}$ estudo dos gêneros neotropicais de Ptychoderini e principalmente das espécies de Hypselotropis Jekel, 1855 demonstrou que $H$. grandis Jordan, 1911 não pertence ao gênero. Desta forma, Unanthribus gen. nov. é proposto para incluir esta espécie e $U$. maximus sp. nov., descrita do Brasil (Pará e Rondônia).

$\mathrm{O}$ material estudado pertence às seguintes instituições (responsáveis pelas coleções, entre parênteses): INPA Instituto Nacional de Pesquisas da Amazônia, Manaus (C. Magalhães); MNRJ - Museu Nacional, Universidade Federal do Rio de Janeiro, Rio de Janeiro (M. A. Monné); MZSP Museu de Zoologia, Universidade de São Paulo, São Paulo (U. R. Martins).

\section{Unanthribus gen. nov.}

Espécie-tipo. Unanthribus maximus sp. nov.

Etimologia. O epíteto é uma combinação das palavras Una, que em tupi significa besouro, e Anthribus. Gênero masculino.
Comprimento (24-27 mm). Corpo alongado, aproximadamente três vezes mais longo que a largura umeral; aspecto robusto, altura ao nível do metasterno, pouco menor que a largura umeral. Rostro alongado, cilíndrico-deprimido, com lados subparalelos, mais estreito na base entre olho e escrobo; ápice largo, a maior largura subigual à largura da cabeça e um terço maior que a largura na base. Dorso do rostro com três carenas longitudinais alongadas: uma mediana, muito estreita e discretamente elevada, estende-se do chanfro apical do rostro e ultrapassa o meio da fronte, deprimida perto do chanfro apical e atenuada sobre a fronte; e duas dorsolaterais, mais engrossadas e retilíneas, estendem-se da margem anterior dos olhos até o nível dos escrobos. Ápice do rostro com chanfro profundo no meio; aos lados, no dorso, fortemente deprimido. Lados do rostro, nos machos, sem carenas, nas fêmeas com carenas atenuadas. Escrobos laterais, mais próximos do ápice do rostro, não elevados; a região anterior, onde acomoda o côndilo do escapo, estreita e rasa; a região posterior, nitidamente mais ampla e profunda; sulco subescrobal evanescente nos machos e raso nas fêmeas. Mento: chanfro apical mediano, amplo e anguloso; próximo da margem apical com sulco estreito revestido por pilosidade; nos machos com uma ampla área deprimida, revestida por pilosidade alongada, subereta e densa; nas fêmeas, a região centro-longitudinal elevada e glabra, a cada lado, com sulco amplo revestido por pilosidade moderadamente alongada, subereta e densa. Cabeça pouco mais larga que longa, vértice subconvexo; lados, atrás dos olhos, finamente pontuados. Fronte discretamente convexa, nitidamente mais estreita perto da base do rostro, ligeiramente

1. Contribuição n 1411 do Departamento de Zoologia, Universidade Federal do Paraná.

2. Departamento de Zoologia, Universidade Federal do Paraná. Caixa Postal 19020; 81531-990, Curitiba-PR, Brasil.

Endereço eletrônico: jrmermudes@uol.com.br

3. Bolsista do CNPq. 
deprimida aos lados, sem carenas laterais. Olhos laterais e amplos; subarredondados, com margem anterior oblíqua; granulação moderadamente grossa, omatídios pouco proeminentes. Labro convexo e transverso; margem apical arredondada. Mandíbulas pouco robustas, margem externa curva; dorso com sulcos profundos; ápices projetados e lisos. Palpos maxilares: artículo apical cilíndrico e alongado, 1/3 mais longo que o anterior, atenuado no ápice; segundo artículo obcônico. Palpos labiais: artículo apical subigual ao basal, 1/3 mais longo que o segundo, expandido para o ápice.

Antenas com dimorfismo sexual acentuado: machos com antenas longas, cerca de duas vezes o comprimento do corpo; antenômeros II-VIII alongados e nodosos no ápice; II-III robustos e engrossados, IV-XI progressivamente mais delgados; clava alongada e delgada. Fêmeas com antenas curtas, ultrapassam a carena antebasal do pronoto pelo ápice do antenômero XI; antenômeros curtos e robustos; clava moderadamente longa e engrossada, aspecto serreado pelas expansões do ápice externo dos antenômeros IX-X e pelo estreitamento apical do XI.

Protórax tão ou pouco mais longo que largo, lados ligeiramente convergentes da carena antebasal para a margem anterior; após essa carena, estreitado.Pronoto ligeiramente deprimido no disco, com discreta elevação antemediana; pronoto com rugas na depressão, na elevação antemediana e, aos lados, próximo das carenas laterais. Carena antebasal elevada, interrompida no meio; carena lateral alongada, retilínea, quase alcança a margem anterior do protórax. Carena secundária alongada e lisa. Segunda carena lateral presente e pouco elevada. Lados do prosterno com pontos setígeros grossos; após a sutura pleural, os pontos mais finos. Prosterno com sulco antecoxal profundo. Processo prosternal curto, sub-ereto e triangular. Coxas anteriores algo projetadas. Mesosterno elevado no disco. Processo mesosternal sub-ereto, largo, cerca de $2 / 3$ de uma cavidade cotilóide média. Coxas mesotorácicas globosas. Metasterno transverso e subconvexo, com sulco anterior profundo e anguloso no meio, aos lados raso e sinuoso; com gibosidade mediana junto ao sulco anterior. Escutelo tão ou pouco mais longo que largo, convexo. Élitros alongados e convexos; na base amplamente elevados e convexos; lados ligeiramente estreitados do quarto basal para o ápice; úmeros projetados e arredondados; margem basal elevada e engrossada perto do escutelo, estreita nos ângulos umerais; no dorso com fileiras de pontos finos; na metade basal, com rugas nos interstícios entre os pontos. Epipleuras declives, com sulco profundo no terço basal, margem elevada e sinuosa. Ápices elitrais subarredondados, com margens elevadas e sinuosas. Declive apical dos élitros com as interestrias 3-9 conspicuamente intumescidas e interligadas, obstruindo a fileira de pontos. Pernas alongadas, as médias pouco mais longas. Fêmures clavados, com pedúnculo curto e clava alongada; metade apical externa com área glabra, fina e densamente pontuada (os pontos não alinhados): subarredondada e com microrrugas no profêmur, ovais e estreitas nos meso- e metafêmures. Tíbias discretamente deprimidas e ligeiramente engrossadas para o ápice; protíbias ligeiramente mais expandidas no lado interno do terço apical; metade interna com franja de cerdas compactas, curtas de cor castanha. Tarsômeros estreitos: I ligeiramente mais longo que o II; unhas apendiculadas, três vezes mais longas que o processo interno.

Abdômen: ventritos, aos lados, com pontos setígeros rasos e esparsos; ventrito I, o mais curto, com projeção intercoxal triangular, com sulco que acompanha a margem anterior. Ventrito $\mathrm{V}$, nos machos, discretamente mais curto que o IV, a margem apical fortemente recurva com ângulos látero-apicais algo projetados; nas fêmeas, subigual ao IV, a margem apical pouco recurva, sem projeções látero-apicais. Pigídio subvertical, mais longo que largo e fortemente deprimido; ápice truncadoarredondado; nos machos sem depressão próximo da margem apical, nas fêmeas fortemente deprimido no meio próximo da margem apical.

Discussão. Unanthribus distingue-se dos demais gêneros da tribo Ptychoderini por apresentar exclusivamente: machos com antenas alongadas, cerca de duas vezes o comprimento do corpo e com antenômeros basais II-V deprimidos no dorso; mento com forte dimorfismo sexual; olhos subarredondados e amplos; coxas anteriores algo projetadas; ventrito V com dimorfismo sexual, nos machos, com a margem apical fortemente recurva e os ângulos látero-apicais algo projetados. Com os gêneros neotropicais compartilha, principalmente, os seguintes caracteres: rostro discretamente deprimido, sem sulco longitudinal e prosterno com sulco antecoxal. Assemelha-se a Ptychoderes e difere de Hypselotropis e de Tribotropis, principalmente por: rostro com carenas dorsolaterais engrossadas; clava antenal com o antenômero XI estreito na metade apical; carena lateral do protórax alongada e presença de uma segunda carena lateral; epipleura com sulco profundo no terço basal dos élitros; sulco anterior do metasterno profundo; metade apical externa dos fêmures com área glabra e pontuada. Difere de Ptychoderes: 1) fronte mais estreita perto da base do rostro; 2) base do rostro, no dorso, discretamente deprimida entre as carenas; 3) carena mediana do rostro estreita; 4) lados do rostro sem depressões; 5) antena dos machos alongada com o dobro do comprimento do corpo, o antenômero XI pouco alongado; 6) pronoto pouco deprimido; 7) prosterno mais convexo no disco, com o sulco antecoxal profundo e amplo; pontuação setígera aos lados do prosterno, após a sutura pleural, com pontos mais finos; 8) élitros nitidamente mais convexos e alongados, na base elevados. Em Ptychoderes: fronte menos estreita perto da base do rostro; rostro, na base, mais fortemente deprimido entre as carenas; carena mediana do rostro engrossada e fortemente elevada; lados do rostro fortemente deprimidos entre as carenas; antenas, nos machos, no máximo, pouco mais longas que o corpo; pronoto mais fortemente deprimido; prosterno desde plano a ligeiramente convexo, com sulco antecoxal próximo das procoxas com profundidade e sinuosidade variáveis; élitros desde pouco convexos a aplanados no dorso, na base com gibosidades desde nulas a manifestas. 
Chave para espécies de Unanthribus

1. Revestimento dorsal com escamas brancas e densas intercaladas por escamas castanho-alaranjadas. Élitros, na metade basal, com as escamas brancas nitidamente mais densas; na metade apical com densas escamas castanho-alaranjadas intercaladas por raras escamas brancas. Lados do rostro com escamas brancas e pontuação rasa, densa e confluente. Antenas dos machos ultrapassam o ápice elitral na metade do antenômero VI. Carena antebasal do protórax sub-retilínea. Lados do prosterno, abaixo da carena lateral, com faixa subglabra, larga entre a margem anterior e a sutura pleural e nitidamente estreita da margem posterior em direção à carena lateral, não alcança a sutura pleural. (Figs. 1-2) BRASIL (Pará, Rondônia) U. maximus sp. nov.

Revestimento dorsal com escamas branco-argilosas intercaladas por escamas castanho-claras. Élitros uniformemente com densas escamas castanhas intercaladas por raras escamas branco-argilosas. Lados do rostro impontuados, com escamas castanhas. Antenas dos machos ultrapassam o ápice elitral no ápice do antenômero VI. Carena antebasal do protórax curva no meio, aos lados mais discretamente curva. Lados do prosterno, abaixo da carena lateral, com faixa larga de escamas castanhoescuras, discretamente mais estreita entre a margem posterior e a sutura pleural. (Figs. 3-4) BRASIL (Amazonas) ....... U. grandis (Jordan, 1911) comb. nov.

\section{Unanthribus maximus sp. nov.}

(Figs. 1, 2)

Macho. Tegumento preto a castanho; antenas e pernas concolores a pouco mais claras. Revestimento: dorso do rostro, cabeça, pronoto, escutelo e metade basal dos élitros com densas escamas brancas, subalongadas, lineares e decumbentes, intercaladas com raras escamas castanhoalaranjadas, mais grossas, semidecumbentes e esparsas no rostro, fronte e escutelo; no vértice, pronoto e metade basal dos élitros as escamas castanho-alaranjadas pouco mais densas. Metade apical dos élitros e pigídio com densas escamas castanho-claras, semidecumbentes, intercaladas pelas escamas brancas, mais esparsas. Vértice, a cada lado, com manchas pequenas formadas por escamas castanho-escuras, curtas e semidecumbentes. Pronoto, com manchas escuras, subovais e alongadas entre os ângulos anteriores e, entre os ângulos posteriores, restritas à carena antebasal e margem posterior. Élitros com manchas escuras: no terço basal, duas grandes e subarredondadas e uma próxima da epipleura; uma pós-mediana e outra antes do declive apical; proximidades da sutura elitral e epipleura com várias manchas escuras menores. Revestimento ventral e pernas com escamas esbranquiçadas, curtas, decumbentes e densas. Disco do prosterno subglabro. Mesoe metasterno e disco dos ventritos com escamas pouco adensadas. Lados do prosterno, abaixo da carena lateral, com faixa subglabra que estende-se da margem anterior e alcança a linha da sutura pleural; outra faixa mais fina, estreita-se da margem posterior em direção à carena lateral e não alcança a sutura pleural. Ângulos anteriores dos ventritos com mancha irregular formada por escamas castanho-escuras; lados dos ventritos com escamas castanho-claras esparsas.

Antenômeros I-IX com micropubescência esbranquiçada, mais densa antes do ápice do IX. Antenômeros X-XI com pubescência castanho-escura, brilhante e densa; ápice ventral dos X-XI com cerdas castanho-escuras, curtas e sub-eretas.

Rostro cerca de 2,4 vezes mais longo que a largura basal; lados com pontos grossos, rasos, densos e confluentes e raras escamas brancas; distância entre escrobo e olho, aos lados, pelo menos 1,5 vezes maior que a maior largura do olho; superfície ventral, na base do rostro, fortemente corrugada. Mento, próximo da margem apical com sulco raso e estreito revestido por pilosidade amarelada curta e densa; com área ampla revestida por densa pilosidade amarelada, fina, longa e ereta. Cabeça: lados, atrás dos olhos, finamente pontuados; orla posterior ventral corrugada; superfície ventral entre os olhos opaca, com pontos rasos, adensados.

Antenas (escapo $=1,2 ; \mathrm{II}=2,7 ; \mathrm{III}=4,3 ; \mathrm{IV}=8,3 ; \mathrm{V}=10,7$; $\mathrm{VI}=11,7 ; \mathrm{VII}=8,6 ; \mathrm{VIII}=15,2 ; \mathrm{IX}=15,2 ; \mathrm{X}=1,5 ; \mathrm{XI}=2,5)$ alcançam o ápice elitral na metade do antenômero VI. Escapo curto, cilíndrico-engrossado, deprimido na face dorsal, com comprimento subigual a dois terços do antenômero II. Antenômeros II-V deprimidos, os IV-V muito discretamente; III um terço mais longo que o II; IV com o dobro do comprimento do III; V-VI subiguais e um terço mais longos que o IV; VII subigual à metade do VI; VIII e IX os mais longos, cilíndricos, delgados e subiguais no comprimento; $\mathrm{X}$ um terço mais curto que o XI; antenômero XI com 1/6 do comprimento do IX, a metade apical estreitada, o ápice arredondado.

Margem anterior do protórax com pilosidade amarelada, longa e densa. Carena antebasal do protórax sub-retilínea, forma um ângulo reto com a carena lateral do protórax na altura da margem posterior da procoxa; carena lateral ligeiramente sinuosa, alcança as proximidades da margem anterior. Carena secundária alongada e lisa, interrompida e atenuada no meio, aos lados mais engrossada, alcança a segunda carena lateral; esta discretamente elevada. Lados do prosterno com pontos setígeros grossos ornados com escamas esbranquiçadas, longas e sub-eretas. Prosterno transversalmente elevado, com raros pontos grossos e rasos; à frente das procoxas com sulco transverso, profundo, amplo e discretamente sinuoso. Mesosterno, no disco, com pontos finos, rasos e dispersos; perto da base do processo mesosternal com duas depressões profundas, subovais e contíguas. Mesepimero e mesepisterno com pontos grossos pouco adensados. Processo mesosternal com sulco longitudinal mediano profundo e estreito, apenas ultrapassa o meio; ápice arredondado, discretamente entalhado no meio, sem expansões látero-apicais. Metasterno, no disco, finalmente corrugado transversalmente e com raros pontos finos; lados do metasterno com pontos setígeros grossos e densos, mais evidentes nas proximidades da margem lateral. 

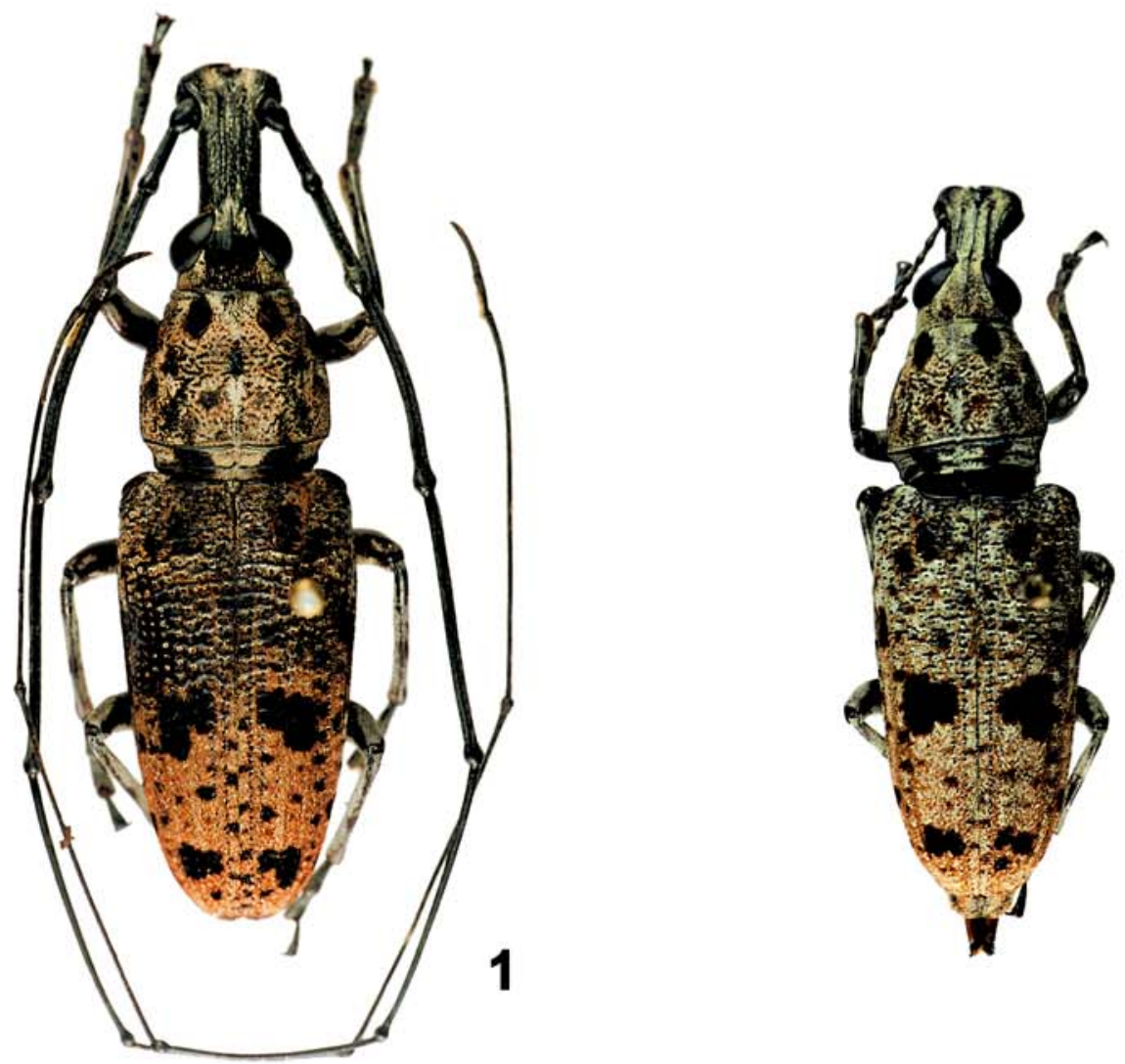

2
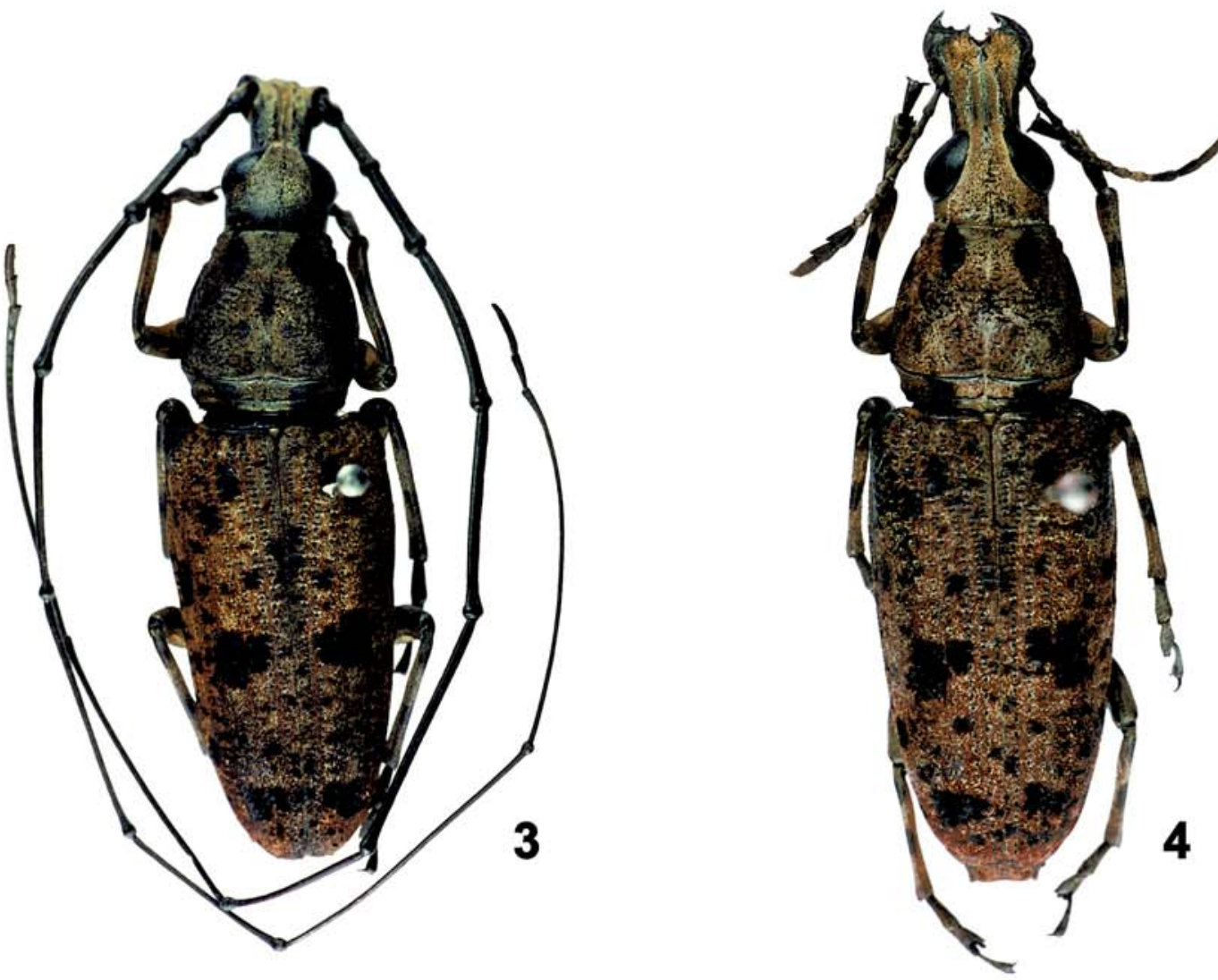

Figs. 1-4. 1, Unanthribus maximus sp. nov., holótipo macho, comprimento (excluído rostro) $27,6 \mathrm{~mm} ; 2$, U. maximus, parátipo fêmea, 21,7 mm; 3, U. grandis (Jordan, 1911), macho, $27,2 \mathrm{~mm}$; 4, U. grandis, fêmea, 23,2 mm. 
Élitros cerca de 2,2 vezes mais longos que a largura basal.

Ventrito II pouco mais curto que os subseqüentes; III e IV subiguais. Ventrito V discretamente mais curto que o IV; ápice recurvo, com ângulos látero-apicais projetados, subarredondados; superfície com pontos grossos, densos e pilosidade sub-ereta.

Fêmeas. Corpo mais curto. Rostro, pelo menos, 1,6 vezes mais longo que a largura basal; distância entre escrobo e olho, um terço menor que a maior largura do olho; lados do rostro com uma carena mais próxima de dorso; no meio com elevação mais engrossada e atenuada (aspecto de carena evanescente), sem depressões entre as carenas; sulco subescrobal raso. Mento: superfície ventral elevada ao longo do meio, fortemente deprimida aos lados, com a pilosidade amarelada mais curta, sub-ereta e densa. Antenas (escapo $=0,4 ; \mathrm{II}=1,9 ; \mathrm{III}=0,7 ; \mathrm{IV}$ $=0,9 ; \mathrm{V}=0,8 ; \mathrm{VI}=0,6 ; \mathrm{VII}=0,6 ; \mathrm{VIII}=0,6 ; \mathrm{IX}=1,0 ; \mathrm{X}=0,8 ; \mathrm{XI}$ $=1,7)$. Ventrito V: subigual ao comprimento do IV; superfície fortemente microesculturada com rugas pouco adensadas; margem apical recurva. Ovipositor) exposto no parátipo) com ápice fortemente esclerotizado, com dois dentes apicais robustos, o dente distal dorso-lateral mais desenvolvido que o ventral e o dente proximal, dorso-lateral, diminuto.

Dimensões, em mm, respectivamente, macho/fêmea. Comprimento total (entre o final da fronte e ápice elitral $=27,6$ / 21,7 ; comprimento do rostro $=6,0 / 3,7$; largura apical do rostro $=4,0 / 3,4 ;$ largura basal do rostro $=2,5 / 2,2 ;$ maior comprimento do escrobo $=1,8 / 1,2$; distância entre escrobo e olho $=3,50 / 1,4$; maior largura superior do olho $=2,2 / 2,0$; maior largura inferior do olho $=1,8 / 1,8$; diâmetro vertical do olho $=2,7 / 2,4$; largura da cabeça $=4,3 / 3,7 ;$ comprimento do protórax $=7,2 / 6,0 ;$ largura do protórax $=7,3 / 6,2 ;$ comprimento dos élitros $=19,3 / 15,0$; largura umeral $=8,8 / 7,7$; altura do corpo (nível do metasterno $=7,8$ / $6,7)$.

Material-tipo. Holótipo macho do BRASIL, Pará, Jacareacanga, XII. 1968. M. Alvarenga col. (MNRJ). Parátipo fêmea: BRASIL, Rondônia, Porto Velho, XI. 1980, O. Roppa col. (MNRJ).

Discussão. Unanthribus maximus distingue-se de $U$. grandis (Jordan, 1911), além dos caracteres mencionados na chave, por: prosterno com pontos mais densos, o sulco antecoxal profundo, amplo e sub-retilínio; mento com sulco da margem apical revestido por pilosidade amarelada curta e adensada, nos machos com área ampla revestida por pilosidade amarelada, fina, longa, ereta e densa. Em U. grandis, os pontos do prosterno são pouco conspícuos, o sulco antecoxal é mais estreito e discretamente sinuoso e o mento é revestido por pilosidade castanha, fina, longa e ereta em toda a superfície.

Unanthribus grandis (Jordan, 1911) comb. nov.

(Figs. 3, 4)

Hypselotropis grandis Jordan, 1911: 92; Blackwelder, 1947: 765 (catálogo); Wolfrum, 1929: 6 (catálogo).
Macho. Tegumento preto a castanho; antenas e pernas concolores a pouco mais claras. Revestimento: dorso do rostro, cabeça, pronoto e escutelo com densas escamas brancoargilosas, subalongadas, lineares e decumbentes intercaladas com escamas castanho-claras, mais grossas e semidecumbentes, raras no rostro e escutelo. Élitros e pigídio com densas escamas castanhas intercaladas por escamas branco-argilosas, estas mais raras na epipleura, declive apical e pigídio. Vértice, a cada lado, com ou sem manchas pequenas formadas por escamas castanho-escuras, curtas e semidecumbentes. Pronoto com manchas escuras subovais e alongadas entre os ângulos anteriores; entre os ângulos posteriores restritas à carena antebasal e margem posterior. Élitros com manchas escuras: no terço basal, duas grandes e subarredondadas e uma próxima da epipleura; uma pósmediana, podendo ser subdividida ou não e outra antes do declive apical; proximidades da sutura elitral e epipleura com algumas manchas escuras menores. Revestimento ventral e pernas com escamas branco-argilosas, curtas, decumbentes e densas. Disco do prosterno e do metasterno subglabros. Mesosterno e região centro-longitudinal dos ventritos com escamas pouco adensadas. Lados do prosterno, abaixo da carena lateral, com faixa de escamas castanho-escuras, apenas pouco mais estreita na porção posterior entre a sutura pleural e a margem posterior do protórax. Ângulos anteriores dos ventritos com manchas irregulares formadas por escamas castanho-escuras; lados dos ventritos com escamas castanhoclaras esparsas.

Antenômeros I-IX com micropubescência brancoargilosa, mais densa antes do ápice do IX. Antenômeros X-XI com pubescência castanho-escura brilhante e densa; ápice ventral dos X-XI com cerdas castanho-escuras, curtas e suberetas.

Rostro cerca de 2,2-2,4 vezes mais longo que a largura basal; lados com escamas castanho-claras esparsas; distância entre escrobo e olho, subigual a 1,2 vezes a maior largura do olho; superfície ventral com pontos grossos confluentes. Mento, em toda a superfície, inclusive no sulco próximo da margem apical até a base ventral do rostro, revestido por pilosidade castanha, fina, longa e ereta. Cabeça: lados atrás dos olhos finamente pontuado; orla posterior ventral corrugada; superfície entre os olhos opaca com raros pontos grossos.

Antenas (escapo $=1,2-1,3 ; \mathrm{II}=2,5-2,7 ; \mathrm{III}=3,4-4,3 ; \mathrm{IV}=6,5$ 7,$3 ; \mathrm{V}=8,2-9,2 ; \mathrm{VI}=9,3-10,3 ; \mathrm{VII}=7,3-7,6 ; \mathrm{VIII}=12,5-12,7 ; \mathrm{IX}=$ $13,3-14,0 ; \mathrm{X}=1,3-2,8 ; \mathrm{XI}=2,2-4,8)$ alcançam o ápice elitral no ápice do antenômero VI. Escapo curto, subigual à metade do antenômero II, cilíndrico-engrossado, deprimido na face dorsal externa. Antenômeros II-V deprimidos na face dorsal; III um terço mais longo que o II; IV um terço mais longo que o III; $\mathrm{V}$ pouco mais curto que o VI; VII um terço mais curto que o VI; VIII discretamente mais curto que o IX; X um terço mais curto que o XI; XI com 1/5 a 1/6 do comprimento do IX.

Margem anterior do protórax com pilosidade castanha, alongada e densa. Pronoto mais discretamente subconvexo, com depressão nitidamente rasa e pouco elevado no meio desta. 
Carena antebasal curva no meio e discretamente direcionada para os lados, forma um ângulo reto com a carena lateral do protórax na altura da margem posterior da procoxa. Carena secundária interrompida e atenuada no meio, nos lados mais engrossada, alcança a segunda carena lateral; esta elevada. Lados do prosterno com pontos setígeros grossos ornados com escama castanha, alongada e semi-ereta. Prosterno transversalmente elevado no disco, sem pontos nítidos; à frente das procoxas com sulco transverso, profundo, estreito e discretamente sinuoso. Mesosterno, no disco, com pontos finos, rasos e dispersos; perto da base do processo mesosternal com duas depressões profundas, subovais e contíguas. Mesepimero e mesepisterno com raros pontos grossos. Processo mesosternal com discreta depressão triangular na metade basal; ápice obliquamente truncado e discretamente entalhado no meio, com discretas expansões látero-apicais. Metasterno grosseiramente corrugado transversalmente, sem pontos; lados do metasterno com pontos setígeros grossos e densos, mais evidentes nas proximidades da margem lateral. Élitros desde 1,9 até 2,2 vezes mais longo que a largura basal.

Ventritos II-IV subiguais. Ventrito $\mathrm{V}$ mais deprimido no disco, com pontos rasos, confluentes, superfície microesculturada, os ângulos látero-apicais projetados, subarredondados.

Fêmeas. Corpo mais curto; rostro pelo menos 1,4 vezes mais longo que a largura basal; distância entre escrobo e olho igual a 2/3 da maior largura do olho; lados do rostro com duas carenas curtas e pouco elevadas; sem depressões entre as carenas; sulco subescrobal raso. Mento: elevado ao longo do meio, fortemente deprimido aos lados, com a pilosidade castanha subalongada, sub-ereta e densa. Antenas (escapo $=$ 0,$5 ; \mathrm{II}=0,9 ; \mathrm{III}=0,8 ; \mathrm{IV}=0,9 ; \mathrm{V}=0,7 ; \mathrm{VI}=0,6 ; \mathrm{VII}=0,7 ; \mathrm{VIII}=$
$0,6 ; \mathrm{IX}=1,0 ; \mathrm{X}=0,9 ; \mathrm{XI}=1,7)$. Ventrito $\mathrm{V}$ : mais longo que o IV; superfície fortemente microesculturada com rugas esparsas; margem apical truncada, ângulos látero-apicais sem projeção.

Dimensões, em mm, respectivamente machos/fêmeas: comprimento total (entre o final da fronte e ápice elitral) $=24,0$ $27,2 / 22,6-23,2$; comprimento do rostro $=5,0-5,8 / 3,6-3,7$; largura apical do rostro $=3,7-4,0 / 3,5-3,6$; largura basal do rostro $=2,2$ $2,4 / 2,5-2,6$; maior comprimento do escrobo $=2,1-2,2 / 1,2$; distância entre escrobo e olho =2,2-2,9/1,3-1,4; maior largura superior do olho $=2,2-2,3 / 2,2$; maior largura inferior do olho $=$ 1,8-2,0/1,7-1,8; diâmetro vertical do olho $=2,7-2,8 / 2,7$; largura da cabeça $=3,8-4,1 / 3,9-4,0 ;$ comprimento do protórax $=6,5-7,3 /$ $6,2-6,3$; largura do protórax $=6,7-7,2 / 6,5-6,7$; comprimento dos élitros $=15,5-18,5 / 15,7-15,8$; largura umeral $=7,8-8,3 / 7,8-8,0$; altura do corpo (nível do metasterno) $=7,3-7,7 / 7,3-7,5$.

Material examinado. BRASIL. Amazonas: $60 \mathrm{Km} \mathrm{N}$ de Manaus, Fazenda Esteio, Cidade Powell, ZF-3 Km-23, 1.VIII.84, B. L. Klein col., 1 macho e 1 fêmea (MZSP), 1 macho, 1 fêmea (INPA).

\section{REFERÊNCIAS}

Alonso-Zarazaga, M. A. \& C. H. C. Lyal. 1999. A world catalogue of families and genera of Curculionoidea (Insecta: Coleoptera) (excepting Scolytidae and Platypodidae). Barcelona, Entomopraxis, $315 \mathrm{p}$.

Blackwelder, R. E. 1947. Checklist of the coleopterous insects of Mexico, Central America, the West Indies, and South America. Bulletin of the United States National Museum 185(5): 765-925.

Jordan, K. 1911. New Anthribidae. Novitates Zoologicae 18(1): 92116.

Wolfrum, P. 1929. Coleopterorum Catalogus, pars 102, Anthribidae. Berlin, W. Junk, 145 p. 